\title{
Involvement of main and vomeronasal systems in modification of oestrous cycle in female laboratory mice
}

\author{
Anna MARCHLEWSKA-KOJ, Małgorzata KRUCZEK, \\ Paweł OLEJNICZAK and Elżbieta POCHROŃ
}

\begin{abstract}
Marchlewska-Koj A., Kruczek M., Olejniczak P. and Pochroń E. 1998. Involvement of main and vomeronasal systems in modification of oestrous cycle in female laboratory mice. Acta Theriologica 43: 235-240.

Housing females in groups prolongs the dioestrous phases in cycling laboratory mice Mus musculus Linnaeus, 1758. Olfactory signals play an important role in interaction between females, and the vomeronasal system is involved in mediation of hormonal responses to pheromones. Present results show that removal of the vomeronasal system (VNX), or bulbectomy (OBX), leads to in decreased numbers of oestrous mice in comparison to non-operated (NON) or sham-operated (SHAM-OBX) singly reared females. Oestrous cyclicity was also affected by social factors. Cohabitation of NON, VNX, OBX or SHAM-OBX females with adult females results in decreased oestrous frequency in comparison to females reared alone. Moreover, VNX females exposed to male bedding inhibited oestrus in comparison to nonexposed VNX animals. The results provide evidence that different external stimuli evoke hormonal responses which are manifested in inhibition of oestrous cycle in female mice.

Department of Mammalian Reproduction, Institute of Zoology, Jagiellonian University, Ingardena 6, 30-060 Kraków, Poland (AM-K, MK, EP); Department of Hydrobiology, Institute of Environmental Biology, Jagiellonian University, Ingardena 6, 30-060 Kraków, Poland (PO)
\end{abstract}

Key words: Mus musculus, olfactory system, oestrus, chemosignals, pheromones

\section{Introduction}

A number of studies have clearly shown that genetic and environmental factors affect dynamics of oestrous cyclicity in mice (Bronson 1989). Abundant evidence indicates that olfactory signals play the most important role in interaction between adult mice. Several investigators have reported that housing female mice in groups prolongs the dioestrous phase (Lee and van der Boot 1955, Bronson and Chapman 1968). Also cohabitation of intact females with ovariectomized females or the presence of their urine inhibits oestrus (Marchlewska-Koj et al. 1983). The opposite effect on females is associated with olfactory stimulants arising from males. Exposure to a male induces regular ovarian cyclicity in previously anoestrous females (Whitten 1956). 
In a series of experiments Keverne and his colleagues (Bellringer et al. 1980, Lomas and Keverne 1982) demonstrated that the vomeronasal organ is involved in the transmission of male pheromones which accelerate puberty in juvenile females and block of pregnancy in adult female mice. The lesion of this system released grouped females from the suppression of oestrus (Reynolds and Keverne 1979). As suggested by the results presented by Johns et al. (1978) the ovulation in female rats reared under constant light can be provoked by male urine stimulating vomeronasal system.

The present study was designed to investigate the possibility of involvement of main and/or accessory olfactory systems in the control of oestrous cyclicity in laboratory mice Mus musculus Linnaeus, 1758 reared in different conditions.

\section{Material and methods}

Adult virgin female and adult male mice from outbred stock bred in our laboratory (maintained as a closed population with maximum avoidance of inbreeding) were used for the experiments. They were maintained in polyethylene cages $(28 \times 15 \times 10 \mathrm{~cm})$ and fed a standard pelleted diet of Murigran (Bacutil, Motycz, Poland) and water. The fine wood shavings used for bedding was changed weekly. The animal room was kept on a $14: 10$ light to dark cycle initiated at $07: 00$, temperature $21-25^{\circ} \mathrm{C}$ and $20-60 \%$ relative humidity.

Females were isolated from males starting from the 24th day after birth and housed 8 to 10 animals per cage. Females were divided into 12 experimental groups at 8-10 weeks of age.

A total of 84 non-operated, 73 vomeronasalectomized (VNX), 79 sham operated (SHAM-OBX) and 53 bulbectomized (OBX) were tested. Surgeries were performed 2 weeks before being tested for their response to social stimuli. During the test 2 tested females were housed for 15 days either alone or with 8 intact mature females. They were transferred to a male-free room with changed photoperiod (lights on 12:00 to 2:00). The light schedule was changed because female mice are more sensitive to male pheromones during the dark phase (Marchlewska-Koj and Kruczek 1986). The mice were allowed two weeks to adapt to the new light schedule. Afterwards each female was transferred to a separate plastic box $(9 \times 9 \times 7 \mathrm{~cm})$ at 10:00 and exposed for $2 \mathrm{hr}$ to clean bedding or bedding of single reared adult male mice. The mouse was removed and returned to its own cage at noon. Each female was tested for 10 consecutive mornings. Male bedding was delivered to plastic boxes just before females were placed there.

Oestrous cycles were determined by vaginal smears immediately examined under microscope every day between noon and 13:00. The first day when the vaginal smear contained only cornified epithelial cells was considered as oestrus.

\section{Surgical procedures and histological verification}

All animals were anaesthetized with pentobarbitone sodium $(0.1 \mathrm{ml} / 10 \mathrm{~g}$ body weight, Polfa, Poland). Surgical procedure were approved by the permission (No 29/95) of the Jagiellonian University Rector's Permanent Committee on the Bioethics of Animal Experimentation.

The vomeronasal organ was removed in a standard procedure described for prairie voles Microtus ochrogaster by Wysocki et al. (1991). Briefly, the females were placed supine in a stereotaxic apparatus, the mouth was opened and a midline incision was made through the palate. A dental drill was used to remove the exposed bone and the vomeronasal organ was then extracted. The wound was closed with cyanoacrylate gel. 
The bulbectomy was performed according to the technique of Leung et al. (1972). The females were laced in a stereotaxic apparatus, a cranial midline incision was made, and after removal of the verlying cranial vault the olfactory bulbs were removed by aspiration. The residual cavity was filled with gelfoam.

The anaesthesia and incision of the sham surgical procedure matched the bulbectomy procedure; he olfactory bulbs remained intact.

For histological verification of OBX and VNX the animals were deeply anaesthetized with pentobarbitone sodium and perfused through the heart with physiological saline followed by fixative $4 \%$ formaldehyde). The brains of the OBX females were carefully removed from the skulls and the extent of bulb removal was microscopically checked. Only complete OBX animals were used for further analysis. The brains of all the VNX animals were removed and embedded in paraffin wax. The olfactory bulbs and frontal poles of the brains were serially sectioned in a horizontal plane at $10 \mu \mathrm{m}$ and stained with Delafield's haematoxylin and eosin. VNX was verified by the complete absence of glomeruli in the accessory olfactory bulbs. Any data collected from VNX animals that had one or more glomeruli in the accessory olfactory bulbs were excluded from the analysis.

\section{Statistical analysis}

Log-linear analysis was used to test for three-way interaction between operation, social conditions, and the number of oestrus (Sokal and Rohlf 1981). To get rid of low frequency cycling females with 0 or 1 oestrus they were treated as one group and females with 2 or more oestrus were treated as another group. Differences in the number of oestrus within experimental groups were tested using Kruskal-Wallis test; subsequently, non-parametic post-hoc comparisons were made (Sachs 1984).

\section{Results}

The results of the oestrous cycle observation during a 10 day period are summarized in Table 1. Log-linear analysis revealed a three-way interaction between operation, social conditions, and the number of oestrus $\left(\chi^{2}=22.43, \mathrm{df}=6\right.$,

Table 1. Number of oestrus (mean $\pm \mathrm{SE}$ ) in non-operated (NON), vomeronasalectomized (VNX), sham-bulbectomized (SHAM-OBX), and bulbectomized (OBX) female laboratory mice. Two tested females were kept for 15 days alone per cage or with 8 intact females. Next, they were exposed to clean or male bedding during 10 days. Numbers of females tested in each surgery variant are shown in parentheses. Those means in the horizontal row marked by the same symbols differ signinicantly from each other: $*-p<0.05$, ** $-p<0.01$, *** $-p<0.001$.

\begin{tabular}{lccc}
\hline \multirow{2}{*}{ Surgery } & Alone clean bedding & \multicolumn{2}{c}{ With 8 female } \\
\cline { 3 - 4 } NON & $2.2 \pm 0.6^{* * *}$ & $1.2 \pm 0.6^{* * *}$ & $1.6 \pm 0.5$ \\
& $(30)$ & $(30)$ & $(24)$ \\
VNX & $1.8 \pm 0.5^{* * *}$ & $1.4 \pm 0.9^{* *}$ & $0.7 \pm 0.6^{* * *}, * * * *$ \\
clean bedding & $(26)$ \\
SHAM-OBX & $(23)$ & $(24)$ & $1.5 \pm 0.5^{*}$ \\
OBX & $2.0 \pm 0.5^{*}, * * *$ & $1.2 \pm 0.7^{* * *}$ & $(28)$ \\
& $(25)$ & $(26)$ & $1.6 \pm 0.6$ \\
& $1.7 \pm 0.5$ & $1.4 \pm 0.5$ & $(18)$ \\
\hline
\end{tabular}


$p<0.01$ ). Thus, the effect of the factors can only be studied within experimental groups.

The results of Kruskal-Wallis test indicate that surgeries influence oestrous cycle in females reared alone $(H=11.62, n=96, p<0.01)$. Post hoc non-parametric test showed that removal of vomeronasal system and bulbectomy resulted in significant decrease of number of oestrus in comparison to non-operated females ( $p<0.05$ and $p<0.01$, respectively). Surgeries influence oestrous cycles in females kept with 8 females and exposed to male bedding $(H=30.42, n=95, p<0.001)$. Post hoc non-parametric test indicates that VNX females cohabited with 8 adult females and exposed to male bedding showed significantly fewer oestrus than non-operated $(p<0.001)$, SHAM-OBX $(p<0.001)$ or OBX females $(p<0.001)$ after the same treatment.

Table 2. The results of Kruskal-Wallis test. The effect of presence of 8 females and male bedding on number of oestrus in non-opereted (NON), vomeronasalectomized (VNX) sham-bulbectomized (SHAM-OBX) or bulbectomized $(\mathrm{OBX})$ female laboratory mice.

\begin{tabular}{lccc}
\hline Surgery & $n$ & $H$ & $p$ \\
\hline NON & 84 & 31.08 & $<0.001$ \\
VNX & 73 & 24.65 & $<0.001$ \\
SHAM-OBX & 79 & 18.32 & $<0.001$ \\
OBX & 53 & 2.63 & ns \\
\hline
\end{tabular}

As shown by Kruskal-Wallis analysis the number of oestruses in tested animals was affected by social conditions (Table 2). Cohabitation of non-operated, VNX or SHAM-OBX females with 8 adult females revealed decreased frequency of oestrus in comparison to females reared alone. Moreover, in VNX females bedding soiled by adult males inhibited oestrous cycling in comparison to nonexposed VNX females. On the other hand, the presence of 8 females and exposure to clean or male bedding did not affect OBX females.

\section{Discussion}

Stimuli from social environment influence the frequency and the course of the oestrous cycle in mice. In high density population different factors - tactile, auditory, visual and olfactory - could have operated during intraspecific encounters. As showed by the results of present experiments in intact, VNX or OBX females reared in crowded condition oestrus was delayed to the same extent. Also cohabitation of females with eight castrated males prolonged dioestrous phases (Marchlewska-Koj et al. 1983).

The olfactory and vomeronasal systems have separate functions. It is generally believed that the main olfactory system is responsible for the majority of functions of nasal chemoreception whereas the vomeronasal system seems to be especially important for mediating reaction of endocrine system to pheromones (Wysocki 1979, Wysocki and Lepri 1991). 
The results of our experiments showed that exposure of VNX females to male bedding inhibited oestrus. This is consistent with finding that oestrous cyclicity was decreased when $\mathrm{E}$ line females were housed with intact or castrated heterogenetic CN males (Barkley et al. 1993). It could be considered that inhibitory effect of male chemosignals is exerted through a different pathway than vomeronasal system. We found earlier that exposure of VNX females to the male bedding increased plasma corticosterone level, whereas exposure to female bedding did not (Marchlewska-Koj et al. 1992).

Similarly to our findings Champlin (1977) demonstrated that in certain strains of mice, bilateral bulbectomy affects oestrous cycle in mice and singly reared OBX females show prolonged dioestrous phase in comparison to SHAM or intact animals. Stress related to surgery and traumatization could be a possible explanation of this phenomenon. Cyclicity in female mice can be modified by different stressors and suppression of oestrus was reported in females stressed by electric foot shock (Marchlewska-Koj et al. 1994). Social interaction between conspecifics, which includes also some stressful activity, is a highly complex phenomenon and therefore it is not easy to identify precisely the causes that evoked endocrine responses.

Acknowledgements: The work was supported by grant BW/IZ/UJ.

\section{Reference}

Barkley M., Delgado DeLeon D. and Weste R. 1993. Pheromonal regulation of the mouse estrous cycle by a heterogenotypic male. The Journal of Experimental Zoology 265: 558-566.

Bellringer J. F., Pratt H. and Keverne E. B. 1980. Involvement of the vomeronasal organ and prolactin in pheromonal induction of delayed implantation in mice. Journal of Reproduction and Fertility 59: 223-228.

Bronson F. H. 1989. Mammalian reproductive biology. The University of Chicago Press, Chicago \& London: $67-75$.

Bronson F. H. and Chapman V. M. 1968. Adrenal-oestrous relationships in grouped or isolated female mice. Nature (Lond.) 218: 483-484.

Champlin A. K. 1977. Strain differences in estrous cycle and mating frequencies after centrally produced anosmia in mice. Biology of Reproduction 16: 513-516.

Johns M. A., Feder H. H., Komisaruk B. R. and Mayer A. D. 1978. Urinary induced reflex ovulation in anovulatory rats may be a vomeronasal effect. Nature 272: 446-448.

Lee S. and van der Boot L. M. 1955. Spontaneous pseudopregnancy in mice. Acta Physiologica et Pharmacologica (Neerl) 4: 75-78.

Leung P. M., Larson D. M. and Rogers Q. R. 1972. Food intake and preference of olfactory bulbectomized rats fed amino acid imbalanced or deficient diets. Physiology and Behavior 15: 381-387.

Lomas D. E. and Keverne E. B. 1982. Role of the vomeronasal organ and prolactin in the acceleration of puberty in female mice. Journal of Reproduction and Fertility 66: 101-107.

Marchlewska-Koj A. and Kruczek M. 1986. Acceleration and suppression of the oestrous cycle in mice by pheromones: The light effect. Folia Biologica (Kraków) 34: 221-226.

Marchlewska-Koj A., Kruczek M. and Toch E. 1983. Suppression of estrus cycle of female mice by ovariectomized females. Hormone and Behavior 17: 233-236. 
Marchlewska-Koj A., Kruczek M. and Zacharczuk-Kakietek M. 1992. Olfactory signals of conspecifics stimulate adrenal function in female mice. [In: Chemical signals in vertebrates VI. R. L. Doty and D. Muller-Schwarze, eds]. Plenum Press, New York: 271-276.

Marchlewska-Koj A., Pochroń E., Galewicz-Sojecka A. and Galas J. 1994. Suppression of estrus in female mice by the presence of conspecifics or by footshock. Physiology and Behavior 55: 317-321.

Reynolds J. and Keverne E. B. 1979. The accessory olfactory system and its role in the pheromonally mediated suppression of oestrus in grouped mice. Journal of Reproduction and Fertility 57: 31-35.

Sachs L. 1984. Applied statistics. A handbook of techniques, 2nd edition, Springer Verlag, New York: 303-306.

Sokal R. R. and Rohlf F. J. 1981. Biometry, 2nd edition, Freeman, New York: 747-761.

Whitten W. K. 1956. Modification of the oestrous cycle of the mouse by external stimuli associated with the male. Journal of Endocrinology 13: 399-404.

Wysocki C. J. 1979. Neurobehavioral evidence for the involvement of the vomeronasal system in mammalian reproduction. Neuroscience and Biobehavioral Review 3: 301-341.

Wysocki C. J., Kruczek M., Wysocki L. and Lepri J. J. 1991. Activation of reproduction in nulliparous and primiparous voles is blocked by vomeronasal organ removal. Biology of Reproduction 45: 611-616.

Wysocki C. J. and Lepri J. J. 1991. Consequences of removing the vomeronasal organ. Journal of Steroid Biochemistry and Molecular Biology 39: 661-669.

Received 25 March 1997, accepted 29 December 1997. 